\title{
Between Smart Technologies and Soviet Guns: imaging the new heroic figure in postdigital warfare
}

\begin{abstract}
In March 2017, I travelled to the frontline between the Ukrainian army and Pro-Russian separatist forces in the Donbass region, East Ukraine, as part of a research project into the return of 20th century weapons in digital culture across Europe. While embedded in a patrol with soldiers of the Ukraine Volunteer Corps, an organization affiliated with the nationalist Right Sector movement, I ended up in a firefight on the edge of the no man's land. I documented how the soldiers alternatingly operated Soviet-era Kalashnikov assault rifles and contemporary consumer technologies, such as smartphones an action cameras. I will read the simultaneous performance of the soldiers with weapon and consumer technologies from different eras from the perspective of Russell Davies' concept of the postdigital, in relation to selfie practices and microcelebrity performance in networked culture. In this context, I will reflect on Alain Badiou's concept of the soldier as 'heroic figure'. In response to Badiou's claim that the traditional soldier is no longer an effective symbolic trope in a highly technologized culture, I will reflect on the - embodied and digitally networked soldiers I accompanied as possible heroic figures of the post-digital.
\end{abstract}

Keywords: consumer technology, warfare, postdigital, selfie, microcelebrity

This work was supported by Arts Council England and the Global Challenges Research Fund. 
In March 2017, I travelled to the frontline between the Ukrainian army and Pro-Russian separatist forces in the Donbass region, East Ukraine. For several years, the Donbass war has hardly been front page news anymore in the rest of Europe, but the conflict continues despite several ceasefire agreements. While large parts of the frontline are usually quiet, unpredictable skirmishes and even heavy shelling regularly occur. I went to Shyrokyne, a destroyed frontline town in the area around Mariupol on the sea of Azov. Here, I was hoping to document uneventful frontline positions of the Ukrainian army to make a work about the everyday practice of alertness and waiting, which usually remain outside news coverage and public awareness outside conflict zones. However, contrary to expectations in this usually rather uneventful part of the frontline, I ended up in a firefight while embedded in a small frontline patrol with soldiers of the Ukraine Volunteer Corps, an organization affiliated with the nationalist organization, Right Sector.

Drawing from this experience, I made a $16 \mathrm{~mm}$ film, patrol (Ploeger 2017) ${ }^{1}$, which consists of footage I recorded with my smartphone during the trip and subsequently transferred to celluloid film. It shows fragments of my foot journey with three soldiers, known under their noms de guerre as Bear, Carpenter and Steinar. The two-minute long film shows how we move from a safe house on the edge of the no man's land to a frontline outpost opposite a separatist position, while installing a communication cable through an unfinished trench (figure 1).

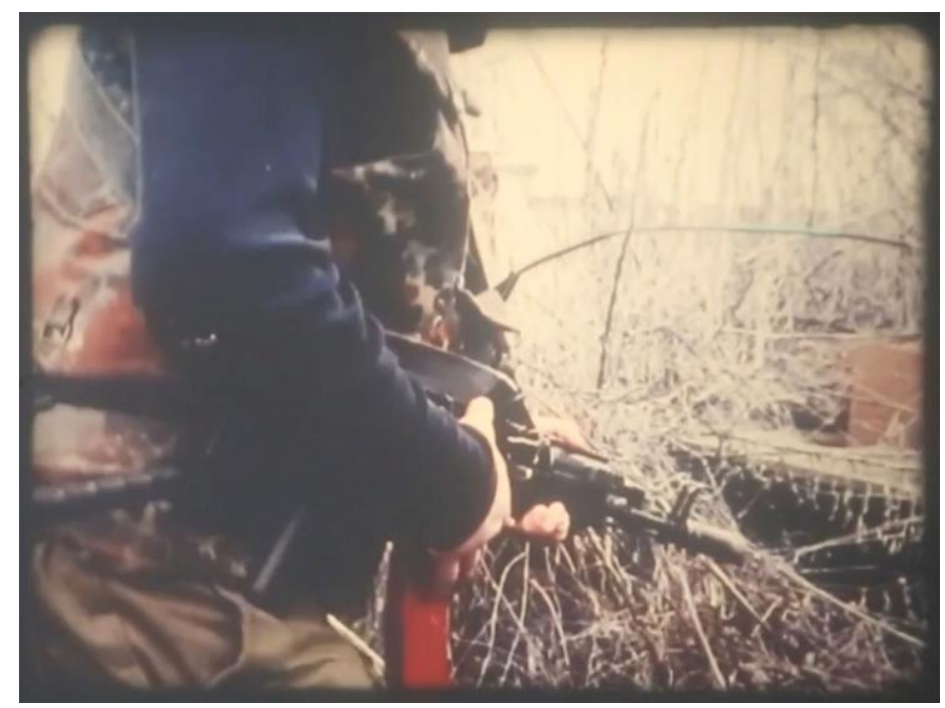

Figure 1. Bear in the trench.

Bear is the commander of the unit. The insignia on his camouflage baseball cap shows a picture of a cartoon-like bear holding a rifle. Carpenter is a jolly middle-aged man with a grey beard, wearing an old red and blue jumper under his open uniform jacket. Steinar, at least 25 years younger, has a much more sophisticated outfit. His American-style battle dress fits perfectly and is complemented by a fashionable-looking camouflagecoloured middle-Eastern schemagh.

I film our journey with my smartphone, adopting the idiom of the medium through the inclusion of several selfie shots (figure 2). I am not the only one documenting though. The soldiers I accompany, as well as many of the others I met at the safe house and the base camp, carry various state-of-the-art mobile technologies with them (figure 3).

${ }^{1}$ https://vimeo.com/259371333 [accessed 29 June 2019] 


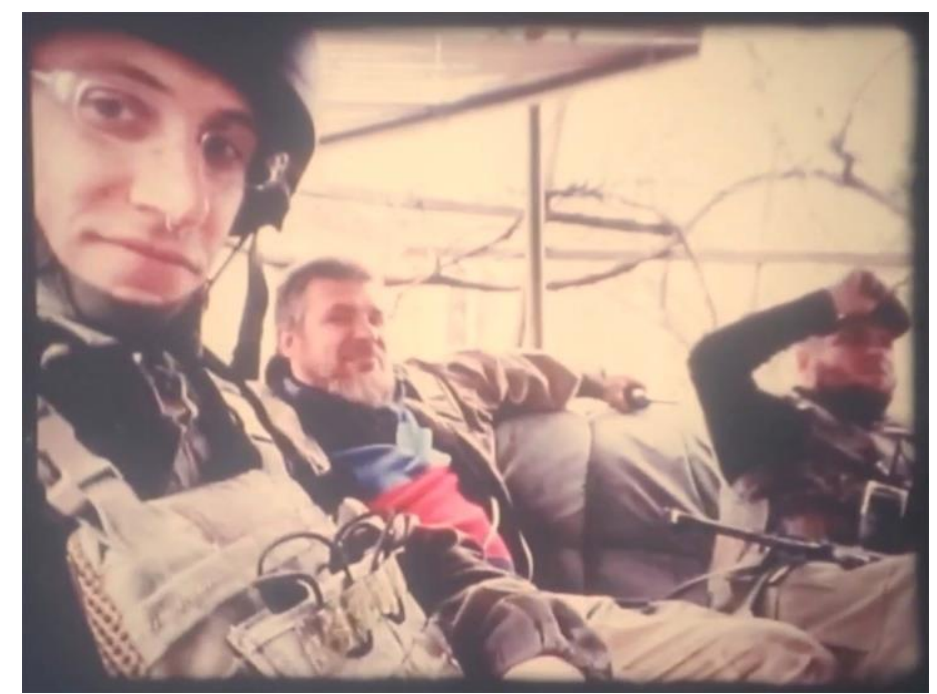

Figure 2. Selfie-shot of the author with Carpenter (middle) and Bear (right)

About halfway through our walk to the outpost, just after we entered the field that constitutes the no man's land, we hear automatic gunfire. "Down, down!" Bear yells. We duck down into the shallow, unfinished trench. As soon as it stops for a moment, we run forward towards the building that will provide cover. Bear and Steinar respond fire through holes in the walls, while Carpenter collects a bazooka from the other side of the trench. Steinar fires with one hand while holding his GoPro action camera in the other. Shortly afterward the GoPro camera is put into my hands and the men indicate that I should film them from behind a little wall. I document how Carpenter runs out into the open field next to the house with the bazooka on his shoulder, while Steinar and Bear follow him to give cover with automatic fire from their AKs.

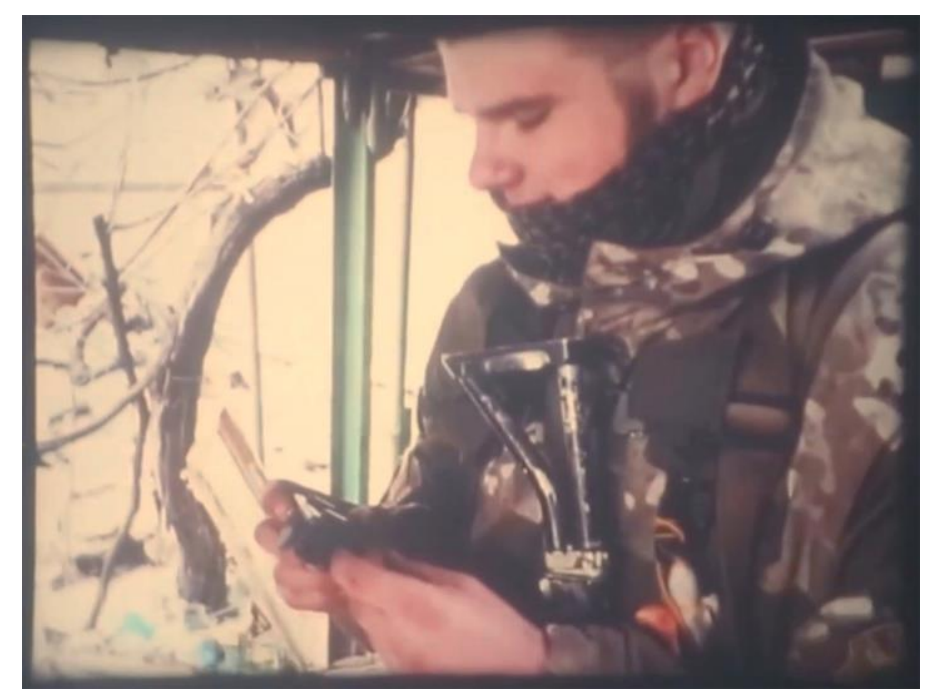

Figure 2. Steinar checking the footage on his GoPro action camera.

Later on, after the firefight has quieted down and while we are on our way back to the safe house, Steinar picks up an unexploded mortar shell and enthusiastically proposes that we let it explode to have some fun. When I refuse to join and ask him to please put it down, he takes off together Carpenter while I accompany Bear to join the other soldiers during their 
break. Shortly after, they return and proudly show us a video of the explosion on one of their smartphones (figure 3).

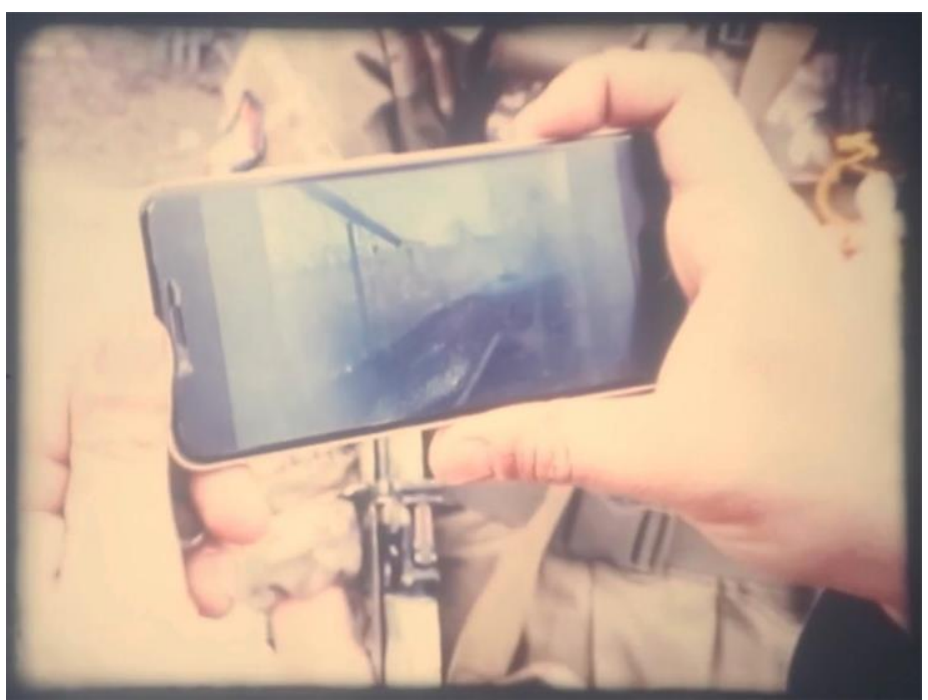

Figure 3. Steinar and Carpenter showing a video of their explosion on a smartphone.

Thinking back of this experience at the frontline, it seems like I was in a split temporality. In some ways, it felt like I went back in time. The soldiers' Soviet-era AK-74S assault rifles and their partly improvised uniforms remind me of film footage of ground warfare in Vietnam ${ }^{2}$ and Afghanistan $^{3}$ in the mid- $20^{\text {th }}$ century (figure 3 ). But this narrative is contradicted by the electronic gadgets that featured prominently at the same time. The soldiers alternately shoot with mid-20 ${ }^{\text {th }}$ century weapons, and contemporary video technologies. Thus, this war seems to be a kind of temporal hybrid where fighters simultaneously navigate a contemporary and an historical technological paradigm. To highlight this hybrid aspect, I chose to transfer the digital video footage, which I shot with my smartphone, to $16 \mathrm{~mm}$ celluloid film, the documentation format of most military conflicts during the second half of the $20^{\text {th }}$ century. Thus, the mediality of the work is 'taken back' to the era of the weapons used.

In exhibitions, the film is played with a film projector with a looper device. I deliberately equipped the projector with a very short lens (16 $\mathrm{mm}$ instead of the usual $50 \mathrm{~mm}$ ) to be able to place it very close to the projection surface. Usually, one would position the projector as far as possible from the screen to minimize the noise from the projector mechanism and avoid distraction from the contents of the film. Instead, my interest was to emphasize the presence of the now old-fashioned medium in the work and thus heighten the perception of the temporal disjunction between military technologies and the consumer devices in the footage. Whereas the prominent presence of the celluloid film medium appears coherent with the weapons and most of the environment, the mobile phones and action cameras seem even more out of place. This heightened juxtaposition of high-tech consumer technology and conventional military technologies in patrolforms the starting point for the reflections in this text.

\footnotetext{
2 See for example this news media footage of American soldiers in the Vietnam War: https://www.youtube.com/watch?v=89 3DgW 7mg [accessed 28 June 2019]

${ }^{3}$ See for example this footage from the AP Archive of the Soviet intervention in Afghanistan during the 1980s: https://www.youtube.com/watch?v=oKtSfxHPdXs [accessed 28 June 2019]
} 
On one hand, we might explain the apparent temporal technological split as a result of specific, local economic and strategic conditions. Consumer electronics like smartphones and action cameras have become so cheap that even the - often economically disadvantaged - volunteer soldiers can afford these. At the same time, they have no access to state-of-the-art military equipment and are usually not trained to use these due to their position as paramilitary volunteers who are not fully recognized as part of the regular armed forces and endowed with a minimal budget. On the other hand, it may form part of a broader issue though. The co-existence of advanced consumer technology and traditional weapon technologies is not unique to this particular place on the perceived outskirts of the European continent. After a period of seeming decline, firearms have regained presence in everyday life in various places across Europe in recent years. Taking this broader perspective, I would like to consider Bear, Steinar and Carpenter's use of hi-tech audiovisual technologies in combination with conventional firearms as a phenomenon that may be symptomatic of a more fundamental development in digital culture.

\section{The return of the armed fighter in postdigital Europe}

Over the past few years, news media in North-America and Western-Europe have reported extensively on the rise of paramilitary movements in the East of Europe, mostly in response to perceived military threats from Russia. The numerous articles and documentaries on right-wing militias fighting in the war in East Ukraine are supplemented by accounts of military training programmes for civilians in Poland, Hungary and the Baltic states. The mainstay of most of these reports is a concern with the militarization of civil society, hence the regular focus on military training of under aged people, the relationship between paramilitary activity and domestic life, and the connection of paramilitary groups with other civil organizations (Losh 2017; Marcinkowski 2016; reuters 2017)

While the phenomena described in these reports are indeed on the rise in Central and Eastern-Europe, the issue of militarization in civilian society is not confined to the geographical areas in Europe that border with Russia. Although not frequently reported in the same alarming tone with regards to its militarizing impact on civilian life, heavily armed soldiers and paramilitary police forces patrol public space in Brussels, Paris and many other metropoles in the West of Europe. Likewise, paramilitary training for children is not unique to Poland and the Baltic States. A look at the UK Ministry of Defense web page on the Army Cadet Force (Armycadets 2018) shows that this is also a paramilitary organization ('one of the UK's oldest, largest and most successful youth organisations'4) where young people between 12 and 18 years old are offered military training (including 'skills in arms' and 'shooting'; Armycadets 2018).

Also in these contexts, a recent intensification can be recognized. Especially since the terror attacks in Brussels and Paris in 2014-15 the presence of firearms in public space for preventative use has visibly increased in these cities, and in 2015, the UK government started a campaign to increase recruitment for the Cadets and facilitate further integration of the Cadet programme in school curricula (Schoolsweek.co.uk 2015).

Considering these things together, aspects of conventional warfare seem to be regaining presence in public life across Europe after a period of relative decline. Since the 1990s, the presence and media representation of firearms in public space in Europe by both state organs and terrorist factions declined in most places. In Western Europe, terrorist and counter-terrorist action with firearms in relation to the RAF in Germany, IRA in the United

\footnotetext{
${ }^{4}$ https://armycadets.com/county/northumbria-acf/about-our-county/ [accessed 11 March 2018].
} 
Kingdom and ETA in Spain greatly declined, while in former Eastern Block countries the public presence of heavily armed police and military waned after the (mostly peaceful) revolutions during 1989-1991. After this time, digital surveillance and state-of-the-art military technologies started to play an increasing role in the perception of warfare and the experience of security for citizens across Europe. From the introduction of the smart bomb and the stealth fighter jet during the first Gulf War, to the deployment of Predator drones and the exponential spread of CCTV surveillance over the last decade.

This increasing prominence of advanced warfare technologies is coherent with a more general development in civil society that has taken place since the 1990s. Whereas from the 1950s until the late 1980s computers and other digital technologies had largely remained the domain of specialists, large institutions and - from the late 1970s - dedicated hobbyists, digital technology started to establish itself as a commonplace component of the domestic sphere after this time. Since the spread of the personal computer in the 1990s, digital technologies have become almost universally available throughout Europe in the form of mobile smart technologies today.

However, in recent years, people's willingness to rely on high-tech solutions to provide public security seems to be declining in large parts of society, both as a means of 'just' warfare abroad (e.g. drones and smart bombs; see Kennedy 2013) and to adequately protect public space at home (CCTV surveillance, big data analysis; see Briggs et al. 2016). The renewed prominence of conventional firearms in civilian life and representations of warfare appears to be concurrent with this shift.

Thus, a paradoxical development has taken place. Whereas the increasing presence of digital-technology-based systems in the mediatization and perception of weapons and security has long been on par with the spread of digital consumer technologies in civilian life, the more recent return of focus on conventional firearms and weapon systems seems especially odd when we consider that it occurs at the point where digital technologies have at last penetrated almost every area of civil life.

Here, the concept of the postdigital, coined by Russell Davies (2009), may provide insight. Davies describes the postdigital as a condition where society has been saturated with digital technology. On the one hand, this would mean that digital technologies have become so commonplace and integrated in the everyday that their presence starts to lose prominence in people's perceptions. This is akin to Mark Weiser's (1996) concept of Silent Computing, which would entail computer technology and its interfaces becoming so smooth that they move to the background of experience. It also reflects concepts of the posthuman, where, in the context of heightened interaction with advanced technologies, the perceived boundaries between humans and their (technological) others are increasingly blurred (Braidotti 2013). On the other, once digital technologies have become omnipresent, the oftentimes hyperbolic promises that were associated with them during their emergence tend to be reconsidered and nuanced. Once you actually live with advanced digital devices, it is easier to realize that although their capabilities are impressive they are not a magical solution to all problems.

\section{Soldiers and consumer technologies}

How can we understand the return of the image of the armed fighter in relation to these possible shifts in the experience of digital technologies? The men I encountered in Donbass might give us a clue. While Bear, Steinar and Carpenter operate assault rifles and other small arms from the mid- $20^{\text {th }}$ century, they also embrace state-of-the art audiovisual technologies, documenting themselves with smartphones and action cameras, and 
communicating via social media. On one hand, they are soldiers of an old-fashioned kind that we until recently had believed to be gradually disappearing from Western warfare. On the other, they seem to be fully integrated participants in contemporary digital culture. Are they the soldiers of a postdigital era?

The first aspect that is striking in this context is the way in which the soldiers' double role as those handling the firearms and the visual documenters of their own actions relates to the writing of Susan Sontag's [year..]. In her discussion on the role of photography in areas of conflict, there is a clear distinction between the soldier and the documenter:

While real people are out there killing themselves, or other real people, the photographer stays behind his or her camera, creating a tiny element of another world: the image world that bids to outlast us all. (Sontag 1998 [1977] : 178)

Contrary to this, Bear, Steinar and Carpenter continuously alternate between operating their weapons - and potentially killing someone, or getting killed themselves - and being behind their various cameras. As mentioned above, at one point Steinar even fires his assault rifle while holding his GoPro camera to record the action at the same time. There seems to be an integration of roles here, where Sontag's statement that 'The person who intervenes cannot record; the person who is recording cannot intervene' collapses. Here, recording has become an integral part of the intervention ${ }^{5}$.

Whether the images the soldiers generate will 'outlast us all' also remains to be seen. It was apparent that their documentation of the frontline is primarily made for exchanges with colleagues and friends (like the smartphone footage of the mortar shell explosion Steinar and Carpenter showed me when they returned after I refused to join them), and informal dissemination through social media. Although such material may circulate on the web for extended periods of time, in most cases it is of a less permanent character than the documentation generated by the press photographers Sontag quite clearly had in mind when she wrote her text in the 1970s. Rather than documenting events to generate news footage to inform a general public about the conflict, the 'other world' the soldiers I accompanied create through their documentary practice appears more connected to the world of entertainment media spectacle.

While they might appear to be anonymous figures of a large army in a technologically archaic military conflict, Steinar, Bear and Carpenter use contemporary consumer technologies to stage themselves like protagonists in a heroic narrative by posing with their guns in a Hollywood-like manner and editing compilations of spectacular firearm actions (figure 5). This resonates with media scholar Theresa Senft's concept of microcelebrity as an online practice that 'involves people "amping up" their popularity over the Web using techniques like video, blogs, and social networking sites' (Senft 2008: 25). This practice affects the ways in which people represent themselves and their environment in digital content and oftentimes motivates users to adopt the visual idioms of popular culture.

The combination of the image of the traditional soldier with microcelebrity practices of digital culture, which I saw with Bear, Carpenter and Steinar, seems at odds with Alain Badiou's reflections on the place of the soldier as cultural trope in early $21^{\text {st }}$ century. In his essay, 'The Figure of the Soldier' (Badiou 2012), he suggests that the continuous overcoming of the boundaries of humanness is the key characteristic of humanity. In this context, he argues that the 'heroic figure' of the warrior or soldier is an important cultural

\footnotetext{
${ }^{5}$ Informal visual documentation by combatants on the frontline already existed before Sontag wrote her essay though. For example, numerous French soldiers during WW1 made private photographs and stereographs while on active military duty (Jalabert and Puton 2014).
} 
image because its 'inhuman' characteristics enable us to imagine that what is considered beyond the accepted limits of humanity. The actions of the hero are the 'luminous appearance, in a concrete situation, of something that assumes its humanity beyond the [assumed] natural limits of the human animal' (2012: 32). For Badiou, the soldier in war is a key figure in this, because they are 'the incarnation of humanity in its becoming, beyond its animal precariousness, beyond its fear-and-trembling before death' (2012: 38-39). Thus, Badiou's concept of the hero is reminiscent of Merleau-Ponty's existentialist discussion of a hero as someone living 'to the limit his [sic] relation to men [sic] and the world' (MerleauPonty in Smyth 2010: 178) in a radical commitment to 'life considered universally' (Smyth 2010: 178). In other words, the heroic figure defies their own, personal death by acting in support of the life-interests of humankind in universal terms. Through this emphasis on the defiance of fear of death, Badiou's account of the heroic figure also appears to allude to mythology, which enables people to come to terms with aspects of life that are beyond understanding or difficult to engage with.

In this context, we might consider the soldier a trickster figure in the sense of Claude Lévi-Strauss' 'The Structural Study of Myth'. Lévi-Strauss suggests that myths are mediations between two antagonistic conditions that are ultimately based on the primal opposition between life and death. Most myths present a trickster character who provides a mediation or resolution of the tension between these two states. Indeed, Badiou suggests that 'the soldier is an affirmative mediation between life and death' (2012: 42).

From antiquity until the late $18^{\text {th }}$ century, the heroic figure usually took the form of the warrior who had an individual personality and whose actions were driven by destiny. Since the French revolution a transition took place though. The heroic figure was now increasingly portrayed as an anonymous character who operated as part of a mass army. Here, the focus was on the power of collective force. However, Badiou argues that this latter image has come in a state of crisis in early $21^{\text {st }}$ culture, the symptoms of which are a return to heroic figures from previous eras who are driven by 'religious sacrifice and bloody fanaticism' (2012: 33). While Badiou doesn't provide a developed analysis of the possible underlying causes or broader context for this crisis, he does - almost as an aside - suggest that the mediating role of the heroic figure has been replaced by 'the strict inhumanity of technological murder and the bureaucratic surveillance of all aspects of life' (2012: 33). Thus, he seems to locate the issue in the increased presence of high-tech warfare and surveillance technologies, which have replaced representations of ground warfare with its associated 'heroic figures'.

The recent upswing in (media) representations of conventional ground warfare and its visual idiom might suggest a tendency to return to heroic figures from previous eras as discussed by Badiou. However, when we look at Bear and his men it becomes clear that this is not necessarily the case. At first sight, their appearance in my film seems to match the description of Badiou's mass soldier. These men form part of a large army and display no apparent special capabilities or characteristics that would set them apart from so many of their colleagues - as well as opponents - who are fighting in this war. However, if we consider their simultaneous participation in digital culture, their supposed anonymity becomes less clear cut.

In these self-representations, they effectively become what Badiou describes as the warrior figure. Thus, through their simultaneous participation in $20^{\text {th }}$ century-style ground warfare and contemporary digital culture, these fighters seem to connect the images of the mass soldier with the individualistic warrior. 
To see what this connection might mean in terms of Badiou's 'figure of the hero' and its mediating role in culture, I will take a closer look at the ways in which self-documentation in digital culture operates.

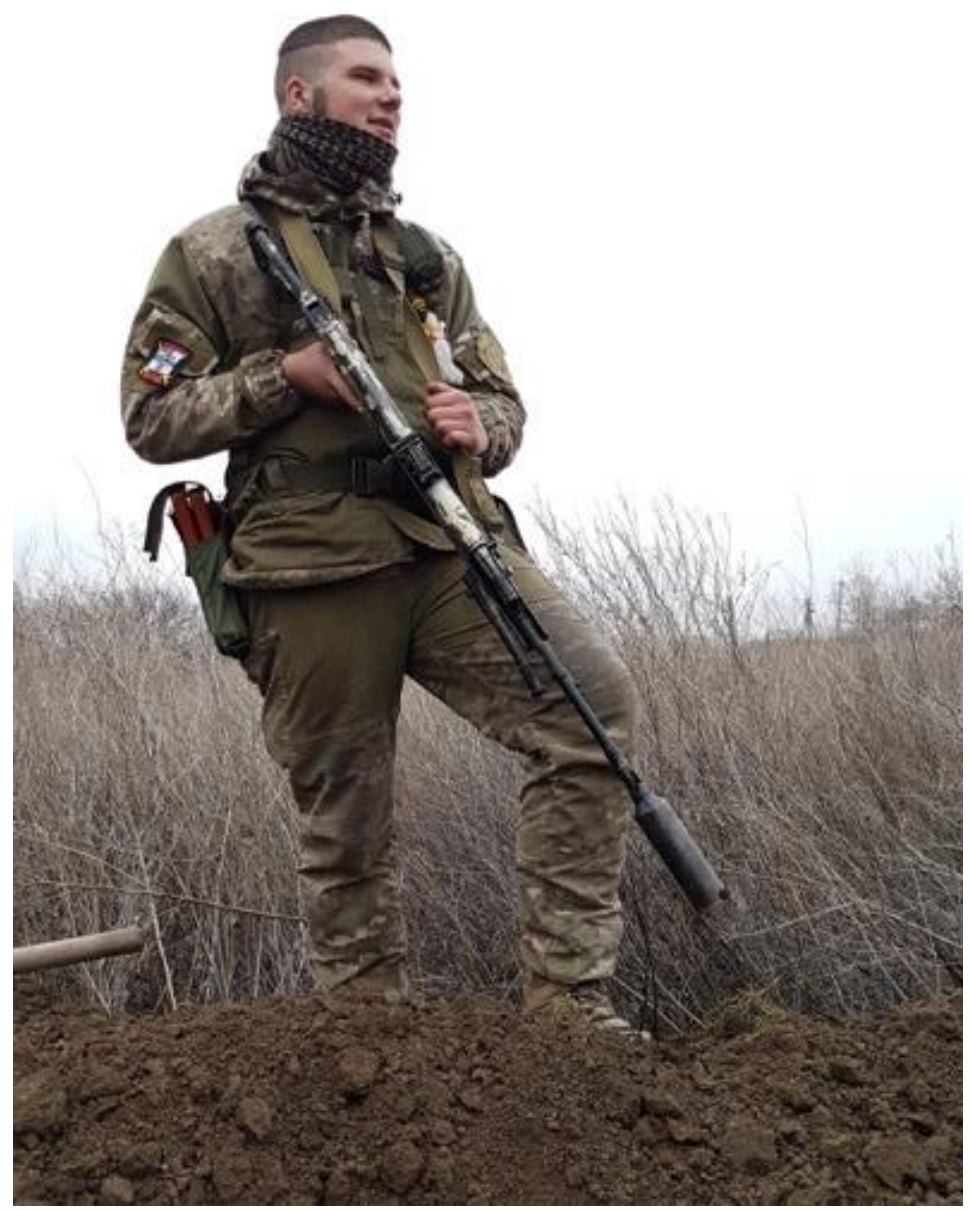

Figure 5. Steinar posing for the camera.

Media scholar Aaron Hess (2015) points out that the popular dismissal of selfies as merely an expression of narcissism in a self-obsessed culture does not acknowledge the multiple ways in which the practice of selfie taking and dissemination engages with various aspects of living in a networked society. Selfies do not only mediate issues related to body and personality. They also show a negotiation of the relationship between body (of the user) and machine (the device used to take the selfie), as well as the connection between the network and materiality. Once a selfie or image of one's environment is circulated online it establishes an element of the physical world as part of the digital realm. If we look at the documentary practice of Bear and his men from this perspective, they effectively bring the images of $20^{\text {th }}$ century warfare into the networked world. At the same time, these images mediate the relationship between the soldiers and their digital devices ${ }^{6}$.

Thus, it becomes clear that Bear, Steinar and Carpenter, act as mediators on two levels. First of all, following Badiou, as infantry soldiers who are exposed to potentially lethal dangers, they are mediators between life and death. At the same time, through their

\footnotetext{
${ }^{6}$ Due to security restrictions I was unfortunately unable to visit the soldiers again to ask them for copies of selfies and other footage from their devices.
} 
becoming-warrior in the digital realm, they offer a mediation between the image of the mass infantry soldier (who - unlike the movie star - represents actual, physical danger) and that of the individual hero who is compatible with the commonplace vision of the high-tech fighter in a media culture of high-tech consumerism (e.g. the protagonists of the Marvel Avengers series). Thus, the role of Bear, Carpenter and Steinar is that of double tricksters: they mediate the opposition between life and death and the (everyday) material and the digital (partly fictional) realm.

\section{The selfie soldier as new heroic figure?}

Could Bear, Carpenter and Steinar be the new heroic figures that Badiou calls for? Although they might seem to operate in the periphery of the continent, their negotiation between hightech consumer devices and conventional weapon technologies offers a response to the seemingly paradoxical Europe-wide phenomenon of remilitarization of public space in the context of highly technologized societies.

They offer an intertwinement of mediations between life and death, and the material and the digitally networked realms. As such, they provide us with an image that might help us to come to terms with existence in a postdigital condition. A condition in which digital technologies have become an omnipresent and taken-for-granted aspect of everyday life, while the promises of salvation through automation that were long associated with digital applications have given way to a continued awareness of the vulnerability and eventual death of our physical bodies. At the same time, the grim reality of the warzone these supposed heroic figures navigate poses a challenge to the optimistic visions of clean and just armed conflict that have been associated with high-tech warfare over the preceding two or three decades.

However, there are several rather perverse dimensions to the suggestion of these far-right soldiers as the new heroes for a postdigital culture. The first becomes apparent while viewing patrol. Watching these contemporary soldiers operate in their trenches might indeed offer a counter narrative to the idealized and cleansed representations of high-tech warfare that have been omnipresent since the Gulf War in the early 1990s. Meanwhile, it also easily facilitates a sense of nostalgia for a cult of masculine violence that would bring back a more 'natural' society. The use of $16 \mathrm{~mm}$ film and the documentary style in patrol, which bears reminiscence of $20^{\text {th }}$ century war propaganda films (see footnotes 2,3 ), foregrounds this nostalgic potential. From such sentiments it is a quick road to Ernst Jünger's (1930) proto-fascist ideal of 'total mobilization' - an involvement of the entire society in the logistics of warfare - as a starting point for a new society that does away with the constraints of bourgeois culture, but at the same time glorifies an authoritarian, masculinist politics.

A second disconcerting aspect emerges when we recall Susan Sontag's mindful words about photography's potential impact on the events it documents:

The omnipresence of cameras persuasively suggests that time consists of interesting events, events worth photographing. This, in turn, makes it easy to feel that any event, once underway, and whatever its moral character, should be allowed to complete itself-so that something else can be brought into the world: the photograph (Sontag 1998 [1977] : 178)

When we regard the soldiers' simultaneous use of firearms and (digital video and photo) cameras from this perspective, a troubling picture emerges. The presence of their own cameras brings the risk that the acts of violence they perform become disconnected from moral concerns and primarily driven by a desire to generate 'good' footage. As discussed above, 'good' here often means in correspondence with spectacular popular cultural 
representations of warfare. In other words, acts of violence may be lead by Hollywoodimaginaries $^{7}$

In this light, it is important to acknowledge the multi-faceted nature of the concept of the hero. For Badiou and Merleau-Ponty heroism is the frame of extraordinary behaviour that may lead to overcoming perceived limitations to human capabilities or existential experiences. However, the concept of the hero - and its counterpart, the villain - is also always subject to ideological and political situatedness. Former Iraqi president Saddam Hussein has often been framed as a hero in news media in the Middle-East, focusing on his positive characteristics and achievements while omitting engagement with the atrocities instigated by him. In contrast, western media channels have predominantly featured the latter and accordingly designated Hussein as a 'dictator' and 'mass murderer' (Al Ali, 2011: 324). Likewise, the perception of Gavrilo Princip, the Bosnian revolutionary who assassinated the Austrian crown prince in 1914, has been cherished as a hero of the Yugoslav cause, and a villain enacting unjustified violence, depending on what aspects of his actions and motivations are foregrounded (Karajica, ...)

Bear and his men may be of interest as 'heroic figures' to reflect on some aspects of (post)digital culture, but we must be cautious of the problematic moral and ideological implications of their framing as such. Possibly, 'heroic figure' is not the most fortunate term for 'inhuman' characters Badiou is after. 'Radical figures' might be a more appropriate designation.

\footnotetext{
7 The impact of Hollywood cinema imaginaries on the enactment of real-life violence has been suggested in other sources as well. Notably, Joshua Oppenheimer's documentary film 'The Act of Killing' (2012) shows the protagonists of the Indonesian mass killings of 1965-66 describing how some of their torture and execution methods were inspired by a desire to recreate scenarios they had seen in movies, albeit without explicitly using cameras to document their actions at the time.
} 


\section{References}

Ali, G., 2011. Hero or terrorist? A comparative analysis of Arabic and Western media depictions of the execution of Saddam. Discourse \& Communication, 5(4), pp.301-335.

Armycadets, 2018. Activities. https://armycadets.com/join-cadets/activities/. [Accessed 5 March 2018].

Badiou, A., 2012. The Figure of the Soldier. In: Philopsophy for Militants. London: Verso.

Braidotti., R., 2013. The posthuman. Oxford: Polity Press.

Briggs, P., Churchill, E., Levine, M., Nicholson, J., Pritchard, G. W., Olivier, P., 2016.

Everyday Surveillance. In: Proceedings of the $2016 \mathrm{CHI}$ Conference Extended Abstracts on Human Factors in Computing Systems (CHI EA '16). New York: ACM.

Davies, R., 2009. meet the new schtick. [online] Available at: http://russelldavies. typepad.com/planning/2009/01/meet-the-new-schtick.html [Accessed 10 Oct. 2017].

Hess, A., 2015. The Selfie Assemblage. International Journal of Communication. Vol. 9, pp. 1629-1646.

Jünger, E., 1930. Die totale Mobilmachung. In: Krieg und Krieger. Berlin: Jünger, Junker and Dünnhaupt.

Karajica, T, 2014. A Hero or Villain, a Terrorist or a Liberator? The Filmic Representation of Gavrilo Princip since the Late 1960s. In: Kazecki, J., Ritzenhoff, K., eds. Heroism and gender in war films. Basingstoke: Palgrave Macmillan.

Kennedy, G., 2013. Drones: Legitimacy and Anti-Americanism. Parameters, 43(4), pp. 2528.

Jalabert, L., Puton, J.-P., 2014. La photographie de la Grande Guerre, affirmation d'un témoignage patrimonial. In Situ, 23. [online] Available at:

http://journals.openedition.org/insitu/10992 ; DOI : 10.4000/insitu.10992 [accessed 28 Jun 2019].

Losh, J., 2017. Ukraine turns a blind eye to ultrarightist militia. [online] Washington Post. Available at: https://www.washingtonpost.com/world/europe/ukraine-turns-a-blind-eye-toultrarightist-militia/2017/02/12/dbf9ea3c-ecab-11e6-b4ff-

ac2cf509efe5_story.html?utm_term=.e13b276b70a8 [Accessed 11 Mar. 2018].

Marcinkowski, B., 2016. The rise of paramilitary groups in Central and Eastern Europe. [online] Neweasterneurope.eu. Available at: http://neweasterneurope.eu/old_site/articlesand-commentary/1862-the-rise-of-paramilitary-groups-in-central-and-eastern-europe [Accessed 11 Mar. 2018].

Oppenheimer, J., Cynn, C., 2012. The Act of Killing. [film] Austin, TX: Drafthouse Film.

Ploeger, D., 2017. patrol. [16mm film] London: Arebyte Gallery. 
reuters.com, 2017. Eyeing Russia nervously, Poles enrol in volunteer militias. [online] Available at: http://www.reuters.com/article/us-ukraine-crisis-poland-militiasidUSKBNOMG24I20150320 [Accessed 26 Sep. 2017].

Senft T. ( 2008) Camgirls: Celebrity and Community in the Age of Social Networks. New York: Peter Lang.

Schoolsweek.co.uk, 2015. Cadet Unites in Schools to Increase Five Fold with 50 Million Budget Boost. https://schoolsweek.co.uk/cadet-units-in-state-schools-to-increase-five-foldwith-50-million-budget-boost/. [Accessed November 20, 2017].

Smyth, B., 2010. Heroism and history in Merleau-Ponty's existential phenomenology. Continental Philosophy Review, 43(2), pp.167-191.

Sontag, S., 1998 [1977]. On Photography. In Crowley, D, Heyer, P., eds., Communication in History: Technology, Culture, Society, $3^{\text {rd }}$ edition. New York, NY: Longman.

Weiser, M., 1996. Ubiquitous Computing.

http://pubweb.parc.xerox.com/weiser/UbiHome.html. [Accessed June 27, 2017]. 